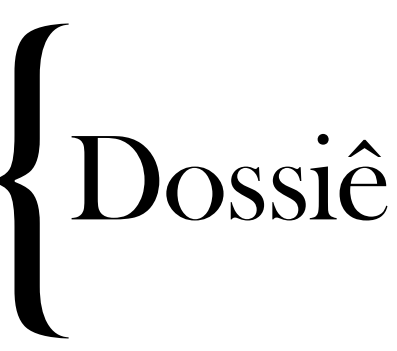




\section{Do nada de $L$ 'Imaginaire ao nada de Drôle de Guerre: o inverso da fenomenologia}

\section{From the nothingness of L'Imaginaire to nothingness of Drôle de Guerre: the inverse of phenomenology}

Este artigo pretende restituir o itinerário ou a "pré-história" do conceito de Nada na filosofia de Sartre; para tanto, utilizaremos aqui L'Imaginaire (1940) e Carnets de la Drôle de Guerre (1938/1940). A partir dessas duas obras, seremos capazes de realizar, digamos assim, uma taxonomia do nada: ver-se-á que este conceito irrompe, primeiramente, como possibilidade que possui a consciência imaginante de operar um recuo nadificador em relação à totalidade do real (n'outras palavras, possibilidade de postular um estado irreal de coisas); depois, nos Carnets (sobretudo os últimos), o nada será identificado ao próprio ser da consciência perceptiva para, finalmente na obra dos anos 1943, aparecer como "operador ontofenomenológico" por excelência da consciência, isto é, como expediente capaz de instituir a abertura (intencional) da consciência ao mundo.

PALAVRAS-CHAVE

Fenomenologia. Ontologia Fenomenológica.

Imaginário. Nada. Existencialismo

The aim of this article is to restore the itinerary or "prehistory" of the concept of Nothing in Sartre's philosophy; for this purpose, we will use here L'Imaginaire (1940) and Carnets de la Drôle de Guerre (1938/1940). From these two works, we will be able to perform a taxonomy of nothingness: we will see that this concept first appears as a possibility that the imaginative conscience possesses to operate a retreat noding to the totality of the real (in other words, possibility of postulating an unreal state of things); then, in the Carnets (especially the last ones), the nothingness will be identified to the very being of the perceptive consciousness, so that, finally in the 1943 work, it will appears as an ontophenomenological operator for excellence of consciousness, therefore, as an expedient capable of establishing the intentional openness of the consciousness to the world.

\section{KEYWORDS}

Phenomenology. Phenomenological Ontology.

Imaginary. Nothingness. Existentialism 


\section{I - O nada fenomenológico de L'Imaginaire}

O Nada, tal como irá emergir na opus magnum sartreana L'être et le néant (1943) ', possui uma "pré-história" que poderíamos buscar em L'Imaginaire (1940) ${ }^{2}$, obra destinada a descrever os mecanismos fenomenológicos da consciência imaginante em oposição à consciência perceptiva ${ }^{3}$, e, depois, em Carnets de la Drôle de Guerre (1938-1940) ${ }^{4}$, série de diários escritos por Sartre durante os primórdios da Segunda Grande Guerra Mundial. Nesta toada, trata-se de fazer indicar que o nada sartreano, tal como o apreendemos ao longo da evolução de seu pensamento filosófico, é passível de uma taxonomia, isto é, de uma classificação que comporta, ao menos, dois momentos distintos dessa mesma filosofia, quais sejam: um primeiro momento fenomenológico, e um segundo momento ontofenomenológico. Isso dito, indiquemos, mui brevemente, a organização teórica do presente artigo: em primeiro lugar, nós iremos tentar restituir o sentido fenomenológico do nada em $I M$, para, em seguida, explicitar seu sentido ontofenomenológico em $C D G$; logo, ao indicarmos estas duas obras, indicamos, ipso facto, a região, por assim dizer, onde nossa taxonomia deverá operar. Feito este rápido preâmbulo, passemos à nossa análise classificatória.

A partir do método fenomenológico da redução eidética, Sartre, em $I M$, buscará deslindar a essência da imagem (seja ela material ou mental), bem como o sentido do ato intencional que anima toda imagem. Sob essa ótica, a consciência imaginante operará a partir de uma intencionalidade (toda consciência imaginante é consciência de algo) que deverá constituir a imagem sem que ela esteja, tal como nas teorias clássicas da imagem, realmente dentro da consciência: daí que a imagem, antes de ser uma coisa na consciência (um simulacro), será uma consciência, isto é, uma intencionalidade. Logo, desde A Imaginação (1936), a metafísica ingênua das teorias clássicas da imagem, tanto do lado da psicologia como do lado da filosofia, operavam um embaraçoso equívoco ao afirmar que a imagem estava, ipsis litteris, na consciência e que o objeto, por seu turno, estava na imagem. Portanto, "fazíamos da consciência um lugar povoado de pequenos simulacros, e esses simulacros eram as imagens" (SARTRE, 2010c,

1 Doravante abreviado como $E N$.

2 Doravante abreviado como IM.

3 Sobre a importância da presente obra no que diz respeito à posteridade do nada, lemos: Sartre redigia a parte crítica do livro sobre L'imagination que lhe solicitara o professor Delacroix para Alcan; iniciara uma parte muito mais original em que reestudava desde a raiz o problema da imagem, utilizando as noções fenomenológicas de intencionalidade e de hylé; foi então que acertou as primeiras idéias-chave de sua filosofia: a absoluta vacuidade da consciência, seu poder de "nadificação" (DE BEAUVOIR, 1980, p. 185).

4 Doravante citado como $C D G$ 

nada de Drôle de Guerre: o inverso da fenomenologia
Dr. Gustavo Fujiwara [UFSP]

p. 17). O que Sartre nomeia como metafísica ingênua da imagem, nos quadros de L'Imaginaire, será designado como ilusão da imanência, ou seja, o hábito que possuímos de pensar no espaço e em termos de espaço ${ }^{5}$. Interrogando a essência da imagem, o filósofo parte de uma análise intencional que permite extirpar a ideia segundo a qual uma imagem seria um simples conteúdo psíquico imanente. A teoria da intencionalidade, todavia, já nos informara acerca da impossibilidade de introduzir esses "retratos materiais" na consciência (estrutura sintética) sem, no entanto, destruí-la por completo. Não sendo nem coisa na consciência, nem uma simples cópia da coisa, a imagem será entendida como um ato, como uma certa maneira que a consciência imaginante possui de reportar-se ao mundo ${ }^{6}$. Na medida em que a percepção apreende $\mathrm{o} X$ qualquer a partir de um ato posicional que visa a presença desse $X$, no caso da consciência imaginante, por sua vez, o ato posicional pode proceder de quatro formas diferentes, quais sejam: a consciência imaginante pode colocar o objeto como inexistente, ausente, existente em outra parte ou neutralizar-se, isto é, não colocar o objeto como existente; "Dois desses atos são negações: o quarto corresponde a uma suspensão ou neutralização da tese. O terceiro, que é positivo, supõe uma negação implícita da existência natural e presente do objeto" (SARTRE, 2010c, p. 32). Assim, no primeiro caso, posso imaginar um centauro ou uma quimera, objetos que não existem; já no segundo, posso imaginar, por exemplo, a biblioteca na qual estudo todas as manhãs mesmo que neste exato momento eu não esteja nela. A partir disso, quando afirmo que possuo uma imagem da biblioteca na qual estudo todas as manhãs, isso equivale a dizer que não a vejo agora e que não estou sentado em uma de suas cadeiras

5 “A maior parte dos psicólogos e dos filósofos adotou esse ponto de vista. É também aquele do senso comum. Quando digo: 'tenho uma imagem' de Pierre, eles pensam que eu tenho no momento presente um certo retrato de Pierre na consciência. O objeto de minha consciência atual seria precisamente esse retrato, e Pierre, o homem de carne e osso, somente seria atingido muito indiretamente, de uma maneira 'extrínseca', pelo simples fato de que é ele que esse retrato representa." (SARTRE, 2010c, p. 19).

6 "A imagem não é, pois, a "presença" na consciência de um "objeto mental" ou de um "simulacro" do objeto exterior. Ela apresenta-nos o objeto ausente, não mais como ele se apresentaria se estivesse efetivamente presente; na consciência imaginante visamos também este objeto no espaço, mas que aparece a nós, então, sob uma forma original, que é a forma imaginante (...)" (JEANSON, 1975, p. 64). Poder-se-ia dizer, sumariamente, que a imagem guarda uma espécie de presença ausente do objeto. Ainda: "De acordo com Sartre, a percepção é uma consciência definida como "abertura à" e que se coloca "em presença" de uma coisa heterógena a ela. A coisa se dá como sendo o que ela, ou seja, como exterioridade. (...) No caso de um ato de percepção, o ato sintético é o resultado de meu aprendizado e de minha iniciação ao objeto. Mas, no caso da imagem, esse ato sintético ultrapassa o aparecer: é ele que cria, então, o objeto. A consciência se dá Pierre por um ato que emprega saberes, intenções e representações. Este ato sintético é constitutivo na imagem, na medida em que na percepção, ele é um resultado. Dito de outra maneira, a consciência não busca mais colocar-se em presença com um ser, ela não se deixa mais solicitar nem seduzir por aquilo que está em face dela: ela tenta, por si mesma, criar uma presença. Pela imagem, ela tenta constranger o real a oferecer o objeto cobiçado a sua apreensão. Dito de outra maneira, o objeto somente obtém uma presença de empréstimo, perdendo sua exterioridade e sua independência” (BREEUR, 2012, p. 263). 
escrevendo. Em outras palavras, viso a biblioteca como ausente; a imagem dá seu objeto como um nada de ser. Quando, por exemplo, produzo uma consciência imaginante de Pierre, o que faço, de fato, é produzir uma síntese intencional que irá reunir uma série de momentos passados para que eu possa afirmar uma identidade através das diversas aparições do amigo ausente: Pierre-em-imagem é a sinonímia de Pierre-intuitivo-ausente; sua imagem é sempre uma certa maneira de não tocá-lo, de não vê-lo a tal distância de mim. O terceiro caso, por sua vez, diz respeito ao irreal que existe alhures (Pierre está em Berlim), e, finalmente, o quarto e último caso, no qual observamos que "a existência do que é imaginado não é nem afirmada e nem negada, mas como já dizia Husserl, colocada entre parênteses ou neutralizada" (CABESTAN, 1999, p. 9).

Todos os quatro atos pelos quais a consciência imaginante põe seu objeto diferem radicalmente do objeto perceptivo, pois o objeto enquanto imagem não nos ensina nada que já não saibamos de antemão. Ao contrário dos objetos da percepção que são dados por perfis (Abschattungen) e nunca de uma só vez, o objeto imaginante é dado de uma só vez: a imagem dá de uma só vez o que ela possui, ou seja, no ato imaginante, já encontramos, desde sempre, o conhecimento do que ele é. Logo, se imagino uma casa, além de apreendê-la por inteira (isto é, sem perfis), sei imediatamente que ela pertence a tal pessoa, que está localizada em tal cidade e conta com seis cômodos; não há espera, não há aprendizado, não há surpresa: o objeto enquanto imagem é apenas o conhecimento prévio que temos dele e nada mais. Finalmente, longe de ser uma simples faculdade entre outras, o imaginário sartreano, radicalmente oposto à percepção, é uma consciência completa que exprime uma potência de negação do mundo, um poder de nadificação da realidade. Ora, mas por que a consciência imaginante postula uma tese de irrealidade que nadifica o mundo? Estando este fato atrelado a uma característica existencial da consciência, Sartre asseverará que o poder nadificador da consciência imaginante é o correlato de sua liberdade intencional, "é porque o homem é transcendentalmente livre que ele pode imaginar" (SARTRE, 2010c, p. 358). Ora, ao contrário de La transcendance de l'Ego ${ }^{7}$, a liberdade, ainda que transcendental e ligada à possibilidade de imaginar (de negar o mundo sob um ponto de vista preciso), agora passa a pertencer ao homem. No mais:

Para que uma consciência possa imaginar, é preciso que ela escape ao mundo por sua natureza, é preciso que ela possa tirar de si mesma uma posição de recuo em

7 Doravante abreviada como $T E$. 
relação ao mundo. Em uma palavra, é preciso que ela seja livre. Assim, a tese de irrealidade nos entregou a possibilidade de negação como sua condição, ora, esta não é possível a não ser pela 'nadificação' do mundo como totalidade (...) (SARTRE, 2010c, pp. 353-354).

Contudo, para que ela possa escapar ao mundo, é necessário que a consciência esteja em situação e não seja um "ente intramundano" ${ }^{~}$. A situação, antes de aparecer em $E N$, já figura aqui como "os diferentes modos imediatos de apreensão do real como mundo" (SARTRE, 2010c, p. 355), ela fornece as motivações concretas e precisas para que o imaginário advenha como nadificação da realidade: ser livre, ser-no-mundo e estar em situação concreta são, finalmente, as condições para que uma consciência produza uma tese irreal. Ser-no-mundo (être-au-monde) resguarda o fato de que a consciência não é uma coisa, um objeto entre outros objetos no interior do mundo real; "ela não está submetida ao encadeamento determinista deste (do mundo), pois ela pode colocar um além irreal do mundo, nadificá-lo" (CABESTAN, 1999, p. 23). Sartre novamente:

(...) para imaginar, a consciência deve ser livre em relação a toda realidade particular, e essa liberdade deve poder definir-se por um 'ser-no-mundo' que é ao mesmo tempo constituição e nadificação do mundo; a situação concreta da consciência no mundo deve a cada instante servir de motivação singular à constituição do irreal (SARTRE, 2010c, p. 357).

É salutar notar, no entanto, que a situação concreta, nos quadros de $I M$, não é forçosamente a situação ${ }^{9}$ tal como ela é, pela primeira vez, teorizada em $C D G$. Lá, sob a influência direta de Heidegger e cada vez mais distante de Husserl, a situação assinala uma rede de determinações contingentes nas quais a liberdade ou se apoia ou recusa; além disso, quando do aparecimento de $E N$, a situação operará a junção entre o fenomenológico e o ontológico, isto é, fará com que a

8 “(...) imaginar supõe que a consciência não esteja 'atolada', 'engolida', 'presa no mundo', logo, que ela não seja um simples ente intramundano, mas que ela escape ao mundo" (CABESTAN, 1999, p. 22).

9 Em IM (2010c, p. 355), “nós chamaremos 'situação', os diferentes modos imediatos de apreensão do real como mundo.” Ademais, ainda que essa situação seja fenomenológica, ela já assinala uma abertura da consciência ao mundo e revela "o absurdo essencial da existência” (SARTRE, 2010c, p. 328) cujo correlativo noemático, no caso de $I M$, será o refúgio no mundo imaginário. 
consciência surja como um ser-no-mundo ontofenomenológicamente rodeada por objetos que possuem seus coeficientes de adversidade; n'outras palavras, no ensaio de ontologia fenomenológica a situação representará a dependência ontológica do ser transfenomenal da consciência face ao ser transfenomenal do mundo, dependência ontológica que desemboca em uma nova faceta da intencionalidade da consciência como fundamentalmente situada. Aqui, bem ao contrário, a situação é eminentemente fenomenológica, ou seja, a consciência está em situação de uma transcendência, pois:

(...) a consciência é transcendentalmente livre, mas esta liberdade está ainda fundada sobre a posição de uma transcendência real e individual. Do mesmo modo que a contingência é uma condição para a realização do ato livre, do mesmo modo uma transcendência real é condição da constituição-nadificação que é a imaginação. (...) a consciência está fenomenológicamente 'em situação', ou seja, sobre o fundo da realidade do mundo (sobre o fundo fenomenológico), e não da realidade do ser (fundo ontológico) (MASSELOT, 2012, p. 11).

Isso significa, sobremaneira, que a imagem somente pode ser negação do mundo se, e somente se, o mundo for apreendido como um conjunto sintético real e capaz de ser ultrapassado. Em outras palavras, o mundo real é pressuposto e deve figurar como o fundo no qual a consciência imaginante age através de seu poder nadificador ${ }^{10}$. Há, desta lida, um díptico entre o real e o imaginário (irreal): a nadificação (irrealização) somente se concebe a partir de uma espessura do real que será nadificado pela consciência imaginante; "assim, colocar o mundo como mundo ou 'nadificá-lo' é uma única e mesma coisa" (SARTRE, 2010c, p. 354). Para que esta "circularidade" entre o real e o irreal fica clara, tomemos de empréstimo o exemplo do filósofo: imaginemos um centauro, objeto inexistente. Para que ele surja como irreal, é preciso que o mundo seja apreendido como "mundo-onde-o-centauro-não-existe", ou seja, é preciso que a consciência se volte para esse mundo real e, em oposição a ele (mas a partir dele), faça surgir o centauro como objeto irreal. Destarte, a imagem, sendo negação do mundo a partir de um ponto de vista particular, "jamais pode aparecer

10 "Todo imaginário aparece 'sob fundo de mundo', mas reciprocamente, toda apreensão do real como mundo implica uma ultrapassagem velada em direção ao imaginário" (SARTRE, 2010c, p. 361). 
Dr. Gustavo Fujiwara [UFSP]

senão sobre um fundo de mundo e em ligação com o fundo" (SARTRE, 2010c, p. 356). Sob uma perspectiva tal, toda consciência realizante, consciência perceptiva, envolve uma ultrapassagem "velada" em direção à consciência imaginante, e esta, por seu turno, somente pode operar a partir de um fundo de mundo real ${ }^{11}$ : eis aqui a situação fenomenológica da consciência, ou seja, sua relação necessária com o mundo transcendente. Além dessa diferença, a nadificação, tal como exposta aqui, ainda não pode ser lida à custa da tópica ontológica (a completa assimilação do ser da consciência como nada de ser): em $I M$, a nadificação, além de dizer respeito exclusivamente à consciência imaginante ${ }^{12}$, deve ser concebida através de um movimento duplo que envolve, simultaneamente, o ato de colocar o mundo como totalidade sintética e o ato de recuar em relação a esse mundo. Assim descrita, a nadificação da consciência imaginante somente opera através da apreensão de uma situação que motiva, après coup, a constituição do objeto irreal. Novamente o filósofo:

É a-situação-no-mundo, apreendida como realidade concreta e individual da consciência, que é a motivação para a constituição de um objeto irreal qualquer e a natureza desse objeto irreal é circunscrita por essa motivação. Assim, a situação da consciência não deve aparecer como pura e abstrata condição de possibilidade para todo o imaginário, mas como motivação concreta e precisa da aparição de tal imaginário particular (SARTRE, 2010c, pp. 355-356).

$\mathrm{Na}$ interdependência da consciência com o mundo real, o conceito heideggeriano de ser-no-mundo é indispensável e sinaliza, como uma de suas consequências, o afastamento de Sartre para com o pensamento fenomenológico de Husserl. Ora, a consciência, sendo um ser-no-mundo, somente pode irrealizar o mundo estando justamente no mundo; daí que ser-no-mundo seja a condição sine qua non para a imaginação: "o nada, para ser exposto, exige a apreensão da totalidade do real, isto é, do mundo como conjunto sintético" (MOUTINHO, 1993, p. 133) ${ }^{13}$. Na medida em que o real figura como a condição da negação,

11 Lemos: "Do mesmo modo, para que meu amigo Pierre me seja dado como ausente, é preciso que eu tenha sido conduzido a apreender o mundo como um conjunto tal que Pierre não poderia estar nele atualmente e a mim presente" (SARTRE, 2010c, p. 355).

12 "É a aparição do imaginário diante da consciência que permite apreender a nadificação do mundo como sua condição essencial e como sua primeira estrutura" (SARTRE, 2010c, p. 359).

13 “A condição para que uma consciência possa imaginar é, portanto, dupla: é preciso, ao 
Dr. Gustavo Fujiwara [UFSP]

a negação, por outro lado, é a condição da afirmação realizante, do real: "se é preciso que o real seja dado de início para que se possa negá-lo, ele apenas é negado precisamente sob a condição de poder ser negado" (VAUDAY, 2005, p. 15); logo, não poderia haver consciência realizante sem consciência imaginante e vice e versa. Segundo Sartre, a consciência imaginante mantém o mundo como fundo nadificado do imaginário e, igualmente, a consciência do mundo (consciência perceptiva, realizante), motiva uma consciência imaginante como apreensão de uma situação particular. Esboçada assim, a relação do real com o imaginário (irreal), portanto, a relação da presença com o nada, conduz-nos a identificar uma nova dinâmica que perpassa aquele velho conceito fenomenológico de La transcendance de l'Ego (1937), a presença. Ora, Derrida, em La voix et le phénoméne (1967), não deixa de observar que Husserl faz da imaginação o modo, par excellence, de apresentação das essências e, com isso, a imaginação deixa de ser apenas uma faculdade entre outras faculdades. Porém, segundo o autor, a concepção husserliana da imaginação permanece tributária de uma metafísica clássica, da reprodução de uma presença que "guarda nela a referência primeira a uma apresentação originária, ou seja, a uma percepção e a uma posição de existência, a uma crença em geral" (DERRIDA, 2009, p. 61). Em suma, a teoria que permite pensar a imagem permanece, em Husserl, uma teoria da re-presentação (Vorstellen). Acerca disso, lê-se:

Para Husserl, como observa Derrida, ainda que a imagem neutralize a existência empírica do objeto imaginado, o que a distingue da experiência perceptiva e da lembrança, ela não inclui menos ali a crença no objeto imaginado. Se o objeto da imaginação não está presente 'aqui e agora', ao menos ele é presentificável. Para dizer de outra maneira, se o objeto da imagem não existe, o próprio da imaginação seria de fazer crer em sua existência a partir de sua representação, o que assinala a marca clássica segundo a qual a imagem, na diferença do conceito, é sempre imagem de um objeto particular (VAUDAY, 2005, p. 12).

Nas tramas da teoria sartreana da imaginação, ainda que esta seja influenciada por Husserl, a imagem não remete a nenhuma presença na exata medi-

mesmo tempo, que ela possa colocar o mundo em sua totalidade sintética e, igualmente, que ela possa colocar o objeto imaginado como fora de alcance em relação a este conjunto sintético, ou seja, colocar o mundo como um nada em relação à imagem" (SARTRE, 2010c, p. 353). 
da em que a consciência imaginante, a partir dos quatro atos posicionais que vimos alguns parágrafos acima, põe seu objeto como um nada. Para Sartre, a incapacidade teórica husserliana está ligada, sobretudo, à impossibilidade do fenomenólogo alemão em operar uma radical distinção entre imagem e percepção: como se sabe, em alguns textos das Recherches logiques (1900), Husserl parte de uma "intenção vazia" pela qual ele pretende dar conta, ao mesmo tempo, da percepção e da imagem mental por um procedimento de preenchimento similar, isto é, de uma mesma matéria. Certamente para o filósofo francês, há uma diferença substancial entre a visada perceptiva e a visada imaginante, isto é, uma diferença de intenção entre uma e outra, diferença que somente pode ser teorizada a partir das sínteses intencionais. Ora, se permanecermos única e exclusivamente em uma diferença superficial de orientação das intenções, seria deveras difícil compreender que, diferentemente da imagem interna, na imagem mental não podemos escolher passar de uma intenção do tipo perceptiva a uma intenção imaginante que visa a mesma hylé. Para que a consciência imaginante seja distinta da consciência perceptiva, far-se-á necessário que a visada da imagem não seja um preenchimento, mas uma visada de uma certa ausência pela qual a matéria da imagem mental, na diferença da perceptiva, seja um conteúdo psíquico. Sob o viés da letra sartreana, Husserl parece ainda "prisioneiro da antiga concepção, pelo menos no que diz respeito à hylé da imagem, que continuaria sendo para ele a impressão sensível renascente" (SARTRE, 1973, p. 108). Portanto, na teoria husserliana da imagem, é como se se tratasse de intenções diferentes animando uma mesma matéria, isto é, "como se se bastasse a intenção para diferir 'carne e osso' de 'ficção"” (MOUTINHO, 1993, p. 122). Destarte, muito além de afirmar uma presença ausente (o que havíamos sumariamente suposto em nota), é preciso convir que a tese irrealizante, a nadificação, "ignora até a ausência do objeto para dispô-lo livremente no imaginário" (VAUDAY, 2005, p. 12), pois a consciência imaginante, a partir da imagem, põe o nada (rien). Sobremaneira, a imagem do $\mathrm{X}$ ausente, antes de visar sua presença, visa sua inexistência: a imagem é o nada do objeto, pois o irreal é sempre um duplo nada, "nada de si mesmo em relação ao mundo, nada do mundo em relação a si” (SARTRE, 2010c, p. 357). Mas, se o ato de nadificação só se realiza a partir de um fundo de mundo (presença), e a presença, por seu turno, traz consigo a possibilidade velada de ultrapassagem em direção ao irreal, poder-se-ia comparar essa relação como a relação que irromperá em L'être et le néant entre o para-si (pour-soi) nadificador e o em-si (en-soi) pleno de ser ${ }^{14}$. Antes de esmiuçarmos a especificidade teórica do Nada

14 Aqui, muito antes de $E N$, já encontramos a relação necessária que deve haver entre o ser e o nada. Na obra de 1943, por conseguinte, o nada será apresentado como um nada de ser "que se coloca por relação à totalidade do real” (MOUTINHO, 1993, p. 141). No mais, a diferença 
Dr. Gustavo Fujiwara [UFSP]

na obra de 1943, diremos que $I M$, a partir do poder nadificador da consciência imaginante, introduz a possibilidade de uma negatividade entre a consciência e o objeto, relação negativa até então ausente dos quadros positivos da fenomenologia teorizada no opúsculo sobre o Ego transcendente. Ainda, diante dessa nova perspectiva, é imprescindível sublinhar que essa consciência, sendo um ser-no-mundo que põe o real como uma situação que deverá ser ultrapassada, deixa-se revelar a si mesma no cogito. Segundo Moutinho (1993, p. 134), esta característica de ser-no-mundo, bem como seu correlato, a nadificação, passam a ser legitimadas pelo cogito, cogito que exige um mundo. Afinal, duvidar do mundo (operação do cogito cartesiano) não é, do mesmo modo, afetá-lo com um coeficiente de irrealidade, ou seja, "a condição mesma do cogito não é de início a dúvida, isto é, ao mesmo tempo a constituição do real como mundo e sua nadificação desse mesmo ponto de vista?" (SARTRE, 2010c, p. 357). Validando a tese irrealizante através da experiência do cogito, Sartre assegura, finalmente, que a consciência imaginante (e seu poder nadificador) não é empírica, mas uma consciência completa realizando sua liberdade diante do mundo, ou seja, podendo nadificar o mundo justamente por ser livre. Há de se notar, desse modo, que há uma relação - como já havíamos indicado acima - entre o nada e o ser ${ }^{15}$, relação que será mantida nos quadros de $E N$ : "o nada somente pode ser dado como uma infraestrutura de alguma coisa" (SARTRE, 2010c, p. 358), doravante, em relação à presença (ao ser), em relação ao fundo de mundo real. Ao contrário do nada de Heidegger que se revela como ente na totalidade, ou seja, como um nada que se dá sem relação nenhuma com o ser, o nada sartreano, modus operandi da consciência imaginante, é "uma experiência que, por princípio, se dá 'com' e 'em"' (SARTRE, 2010c, pp. 358-59); nesta lida, insiste Sartre, mesmo que o imaginário não seja posto de fato, a possibilidade de ultrapassar o existente está aí, é dada a partir do próprio existente e da liberdade nadificadora da consciência imaginante. Logo,

entre em-si e para-si consta, ainda que não nos quadros de uma ontologia, na "Introdução" de A Imaginação. Lá, Sartre observa a diferença entre a folha branca (com suas características) e a consciência: "sua forma, sua cor, sua posição (...) são para mim, não são $e u$. Mas também não são outrem, isto é, não dependem de minha espontaneidade, nem da minha, nem da de outra consciência. São, ao mesmo tempo, presentes e inertes. Essa inércia do conteúdo sensível, frequentemente descrita, é a existência em si. De nada serve discutir se esta folha se reduz a um conjunto de representações ou se é ou deve ser mais do que isso. O certo é que o branco que constato não pode ser produzido por minha espontaneidade. Esta forma inerte que está aquém de todas as espontaneidades conscientes, que devemos observar, conhecer pouco a pouco, é o que chamamos uma coisa. Em hipótese alguma minha consciência seria capaz de ser uma coisa, porque seu modo de ser é precisamente um ser para si. Existir, para ela, é ter consciência de sua existência. Ela aparece como uma pura espontaneidade em face do mundo das coisas que é pura inércia. Podemos, pois, colocar desde a origem dois tipos de existência: é, com efeito, na medida em que são inertes que as coisas escapam ao domínio da consciência; é sua inércia que as salvaguarda e que conserva sua autonomia" (SARTRE, 1973, p. 41).

15 Este ser, obviamente, não é ainda aquele de $E N$. 
(...) o imaginário é (...) um poder de ruína e de fuga, que desfaz o mundo não para destruí-lo ou transformá-lo, mas para desrealizá-lo e fugir dele, para 'nadificá-lo' diria Sartre. O imaginário não é um outro mundo oposto ao mundo tal como ele é, um mundo refeito novamente tal qual o da utopia, mas a negação mesma da mundaneidade e seu constrangimento. É com esta introdução da negatividade como sentido imanente da consciência imaginante que Sartre realiza uma lacuna, não somente em relação à filosofia clássica, mas ainda em relação à fenomenologia de Husserl (VAUDAY, 2005, p. 11).

Mas, finalmente, que lacuna seria essa? Ora, se a fenomenologia de Husserl, como não deixamos de observar, parte da presença, "do presente-vivo" (presença que um Derrida, como notamos, criticará), o filósofo francês, ao enxertar o nada e validá-lo a partir do cogito, reorienta essa presença (o X da consciência perceptiva) ao instituir a possibilidade de sua ultrapassagem, possibilidade que culmina na nadificação desta e, consequentemente, na irrupção de um mundo irreal avesso ao mundo real. Nesta perspectiva, Sartre institui, na presente obra em curso de análise, o avesso da fenomenologia da presença, o avesso, portanto, da positividade sob a qual a consciência e o mundo eram concebidos em TE; no entanto, sejamos cautelosos ao identificar e comentar este avesso. Expliquemo-nos. L'Imaginaire, ainda que postule o poder nadificador da consciência imaginante, o faz sob as dependências da presença, de um existente que, em si mesmo, contém a possibilidade de ser ultrapassado pelo nada: fato que assinala a persistência da presença fenomenológica e que deverá, por conseguinte, reaparecer no ensaio de ontologia fenomenológica dos anos 1943 (a relação do para-si com o em-si, do nada com o ser). Assim, fazendo com que o nada surja no horizonte da presença, Vauday (2005, pp. 8-9) recorre à imagem da fita de Möbius ${ }^{16} \mathrm{a}$ fim de ilustrar a inversão que Sartre imprime na fenomenologia sem, todavia, abandoná-la. Na medida em que o filósofo "cola" o nada à presença, ou seja, na medida em que o existente contém o nada como seu ultrapassamento e o nada só se desvela a partir desse existente, $I M$ descortina, além da pré-história do nada, o sentido de uma ontologia (vindoura) que, todavia, ainda se afirma aqui como fenomenológica. Se a consciência imaginante, a partir de uma tese irrealizante, nadifica a presença, e, a partir disso, faz advir o mundo irreal, é preciso convir que esta articulação entre constituição e nadificação:

16 "Sabe-se que a fita de Möbius consiste em imprimir uma torção em uma fita, seja de papel ou de outro material, e acrescentar nela duas extremidades para obter uma superfície contínua sem dentro e sem fora" (VAUDAY, 2005, p. 8). 
Dr. Gustavo Fujiwara [UFSP]
(...) é sugerida em um quadro transcendental no qual Sartre explicita a imaginação como condição de possibilidade da consciência, sendo entendido que este ato seria impossível se a consciência não se relacionasse, fenomenologicamente, com uma realidade transcendente. Mas, em 1940, Sartre não pode evidentemente querer dizer que a consciência imaginante é ontologicamente relativa ao em-si, mas apenas que ela é fenomenologicamente relativa a uma transcendência real (MASSELOT, 2012, p. 4).

O que realmente L'Imaginaire indica (isso nós já dissemos), e que depois será mantido (embora reconfigurado ao nível do ser), é a impossibilidade de postular uma tese irrealizante sem que haja, necessariamente, um fundo de mundo real (presença). Sob essa ótica, ver-se-á que os Carnets (e posteriormente EN) assumem a impossibilidade de pensar o nada sem a dualidade que este mantém com o ser (dualidade que, em $I M$, é dada pelo real e o irreal). No mais, essa potência nadificadora da consciência imaginante assinala um primeiro indício de nadificação do cogito, e que mais tarde, sobretudo em $E N$, remeterá a uma "falta de ser" constitutiva do ser do para-si ${ }^{17}$, uma descompressão de ser sobre a qual o desejo será teorizado. Isso dito, devemos indagar como o nada, até então exclusivamente pertencente ao imaginário, passa a ser a própria consciência.

\section{II - O nada ontofenomenológicos dos Carnets}

A tônica dos Carnets é a de repensar, em situação de guerra ${ }^{18}$, os conceitos que, no "período fenomenológico" de Sartre, apareciam galvanizados por

17 "O para-si não pode manter a nadificação sem se determinar como falta de ser. Significa que a nadificação não coincide com uma simples introdução do vazio na consciência" (SARTRE, 2010a, p. 121). Será prudente adiantar, ademais, que a falta de ser, falta dita existencial, estará na origem de todos os desejos e vontades do para-si. Antes de EN, Sartre teoriza esse tema no "Caderno XI" de Drôle de Guerre.

18 Sobre a história da redação dos Carnets, lê-se: Ora, quanto a Sartre em guerra, nós dispomos de um documento inestimável que expõe, dia a dia, como ele vive e pensa o que lhe acontece: trata-se, precisamente, dos Carnets de la drôle de Guerre. Tendo comprado, em 14 de setembro de 1939, 'uma caderneta de couro', Sartre pretende redigir, de acordo com os termos que ele inscreve de maneira escolar e profunda na primeira página quadrilhada, um 'Diária de guerra"', empreitada na qual ele irá se debruçar como tenacidade até abril de 1940. Ele redigira, a partir de uma letra pequena, quinze cadernos. Seis chegaram a nós; sabemos que alguns foram destruídos - durante a guerra, ou, mais tarde, em janeiro de 1962, quando o apartamento de Sartre foi explodido pela O.A.S -, outros talvez ainda existam, mas não foram ainda localizados" (SIMONT, 2010, pp. 1365-66). 
uma filosofia estóica (a dessolidarização de si, a radical autonomia da liberdade transcendental de La transcendance de l'Ego, a consciência, etc.). Do estoicismo à autenticidade, da consciência absoluta e transcendental à consciência humana e nadificadora, eis-nos em presença de uma série de reflexões que estão na origem de muitas das obras vindouras de Sartre. Assim, em Drôle de Guerre (plano da análise existencial), espécie de esboço do Ensaio de ontologia fenomenológica, o filósofo tece importantes diretrizes teóricas para que se compreenda o teor desta nova imagem do Nada, et pour cause, da consciência. Assim como ocorrerá posteriormente nos anos 1943, é preciso observar que a questão do nada, aqui, será evidenciada a partir de uma análise minuciosa da liberdade e, depois, da negação. No Caderno $V$, por exemplo, Sartre indica que a negação somente pode ser introduzida pela liberdade (o que, aliás, $I M$ afirmou a partir da dynamis nadificadora da consciência imaginante): "a negação só pode ser introduzida pela liberdade, no mundo, pois a liberdade está toda ela tomada pelo Nada. A liberdade é seu próprio nada. (...) Por meio da liberdade é que podemos imaginar, isto é, anular e tematizar ao mesmo tempo os objetos do mundo" (SARTRE, 2010b, p. 416). Até aqui, nada de novo em relação ao nada tal como ele aparecia em $I M$ não fosse, alguns parágrafos mais adiante, a seguinte conclusão: “esse Nada é um Nada que nós somos" (SARTRE, 2010b, p. 418). Os Carnets dão um passo decisivo ao mobilizarem a nadificação no princípio mesmo da consciência. Sob essa perspectiva, o Caderno XI aborda o problema da negação a partir de dois eixos distintos, quais sejam: a negação externa e a negação interna (dois tipos de negação que irão reaparecer em L'être et le Néant e farão corpo com o tema da constituição ou relação entre para-si e em-si). A primeira negação, externa, é aquela na qual o curso de minha consciência postula, por exemplo, que "a mesa não é o tinteiro" ou que "o papel não é poroso", na medida em que "não está no ser do papel o não-ser poroso" (SARTRE, 2010b, p. 460). Tal assertiva, no entanto, modifica-se completamente quando dizemos, agora, que a consciência que nós somos é a própria negação, por exemplo, "a consciência não é extensão". Acerca dessa negação interna, o filósofo:

Sem dúvida, se nos limitamos a dirigir esse julgamento à consciência de outra pessoa, considerando-a como um dado revelado pela experiência, seremos levados a colocá-la na categoria dos julgamentos precipitados e dir-se-á que negamos a dimensão da consciência como a porosidade do papel. Entretanto, quando se trata da consciência que nós somos, o caso é diferente, pois ela própria é o seu nada de dimensão. Isso quer dizer que não há aqui 
terceiro homem para constatar que duas substâncias inertes, a consciência e a extensão, não possuem relação de dependência entre si. Mas faz parte do ser da consciência não ser extensão (SARTRE, 2010b, p. 460).

Ao contrário da primeira, a segunda negação (interna), toma o não como uma característica existencial, “ou, se se quiser, o não já não mais no nível do juízo, mas como modo de ser" (MOUTINHO, 1993, p. 143); modo der ser exclusivo, notemos aqui, do para-si enquanto ser ek-stático que se transcende para fora de si mesmo rumo ao objeto transcendente (esta é, aliás, uma das diferenças - de ser - fundamental entre o ser-para-si e o ser-em-si). Ora, não existindo um terceiro homem para constatar que a consciência não é extensão, devemos assumir que a própria consciência deve ser como não sendo a extensão, ela mesma sendo seu próprio nada de extensão. N'outras palavras, para que a consciência possa realmente não ser extensão, "é preciso que contenha no mais profundo de seu ser uma relação unitária com essa extensão que ela não é" (SARTRE, 2010b, p. 461). Pertencendo à estrutura íntima da consciência o não ser dimensão, faz-se necessário que ela contenha no mais profundo de seu ser uma relação unitária com essa extensão que ela não é: "trata-se, evidentemente, de uma relação original de ser entre dois seres" (SARTRE, 2010b, p. 461), ou seja, é indelével que a extensão esteja presente à consciência, embora não sendo a consciência, "não somente não sendo nela a extensão, mas não sendo nada (rien)" (SARTRE, 2010b, p. 461). Doravante, a unidade sintética entre a consciência e a extensão é uma unidade negativa na qual a consciência não é a extensão se não na medida em que ela não é ela mesma, na medida em que ela é nada (rien), pois "nada de positivo vem compensar o não-ser-extensão (ne-pas-être-étendue)" (SARTRE, 2010b, p. 461). Sendo seu próprio nada, a consciência, portanto, não é extensão. Sendo não-extensão, a consciência é tomada pelo Nada, ela é aquilo que não é a extensão, ela é o que não e não é o que é.

(...) precisamente porque a consciência se define como sendo o que ela não é e não sendo o que ela é, ela não pode simplesmente ser o que não é a extensão. Seu modo de ser o que não é a extensão é todo ele tomado pelo Nada, ela é aquilo que não é a dimensão sob o modo nadificador do reflexo e do refletido, o que vale dizer que a fórmula 'a consciência não é extensão' deve ser corrigida para 'a consciência não é $a$ extensão' (...) (SARTRE, 2010b, p. 462). 
Dr. Gustavo Fujiwara [UFSP]

A passagem, de aparência obtusa, pode ser simplificada por nós da seguinte forma: a consciência, para ser consciência de si mesma, precisa ser consciência da extensão sem, no entanto, ser a extensão; em outras palavras, ela é consciência da extensão estando consciente de não ser a extensão (ela é consciência de extensão na exata medida em que, enquanto consciência, ela não é extensão). Afinal, como observa Sartre, se a consciência fosse o que ela é, logo, se ela existisse sob a forma do em-si, ela seria a extensão. Sobremaneira, a consciência somente pode ser nadificação da extensão sendo, por sua vez, consciência dessa extensão, o que implica afirmar que a nadificação da consciência apenas se realiza a partir de seu contato com o ser-em-si. No mais, vislumbramos aqui, ainda que reorientada a partir do Nada, a ideia de proximidade absoluta tal como esta é compreendida no ensaio sobre o Ego transcendente ${ }^{19}$ : lá, podemos observar que a consciência é consciência de si mesma quando de sua apreensão do X qualquer. Nesta apreensão, contudo, ela não se deixa confundir com o objeto e muito menos o põe à maneira de uma representação. Na obra em comento, tal como soava ocorrer outrora em $T E$, temos essa mesma proximidade absoluta, mas com o adendo de que ela é dada a partir do Nada de Ser que é a própria consciência. Mantendo uma relação íntima com o ser que a consciência não é, o Nada somente aparece a partir desse ser: "o para-si não pode surgir senão em ligação com a totalidade do em-si que o encerra. O para-si retém diante de si e em torno de si o em-si que ele não é" (SARTRE, 2010b, p. 462); para não ser, o para-si necessita do Ser. Em estridente diferença para com L'Imaginaire, a negação, enquanto sendo a própria consciência, não deve ser entendida como a negação efetuada pela consciência imaginante, ou seja, não devemos conceber esta nova negação inerente à estrutura da consciência

19 Reduzida exclusivamente à visada intencional, a consciência sartreana, em regime de $T E$, segue um programa filosófico que almeja extinguir as filosofias do espírito; a questão relevante, tal como ela fora posta em Situations, IX (1987), era a seguinte: "como dar ao homem de uma só vez sua autonomia e sua realidade por meio dos objetos reais, evitando o idealismo e não caindo, por conseguinte, em um materialismo mecanicista?” (SARTRE, 1987, p. 104). Logo, se o idealismo comete o erro de submeter a realidade do mundo aos processos cognoscentes do sujeito do conhecimento, o realismo, por seu turno, falha ao supor que a veracidade do mundo seria atestada através de uma sensação psicofísica que operaria, via corpo, a articulação do exterior ao espírito. Em suma, enquanto o idealismo assevera que a realidade só pode ser constatada a partir de um espírito que lhe confira validade, o realismo trata a sensação e os vividos "como estados psíquicos de pessoas empíricas, como fragmentos de um mundo de fatos objetivos submetidos às leis da natureza" (COOREBYTER, 2003, p. 18), estando próximo, portanto, de um materialismo que nega a intencionalidade da consciência ao privilegiar as formas deterministas. Em eminente oposição a tais teorias, a démarche fenomenológica-intencional assegura, como notamos, a autonomia da consciência e do mundo: o objeto possui uma independência em relação a estas formulas substanciais (entendimento, sensação) operadas internamente pelo sujeito, sujeito que agora mantém uma proximidade absoluta com este objeto sem, no entanto, determiná-lo ou orientá-lo a partir de processos interiores. Com o itinerário da visada intencional, observamos que o mundo e a consciência são duas instâncias fundamentais um para o outro: por intermédio do mundo a consciência é consciente de si e consciente do objeto. A relação entre o ser transcendental (consciência) e o ser transcendente (objeto) figura como o próprio fundamento da intencionalidade, como o caminho de retorno ao concreto. 
Dr. Gustavo Fujiwara [UFSP]

como uma fuga para fora do mundo à medida que, agora, o movimento de nadificação do para-si não é um recuo, destarte: "se a nadificação fosse acompanhada por um recuo, ela seria nadificação de nada (rien) e recairia no em-si" (SARTRE, 2010 b, p. 463). Sendo a consciência um Nada de ser, a nadificação implica, imediatamente, uma aderência do mudo ao para-si; e este mundo, estado presente à consciência pelo fato de ela ser um nada, é a transcendência: eis aqui o que Sartre chama de ser-no-mundo. De acordo com o filósofo, o em-si (a transcendência, o mundo e os objetos mundanos) "investe a consciência para ser ultrapassado por ela no Nada" (SARTRE, 2010b, p. 463), no Nada que é a própria consciência. Esta consciência, definida pelo Nada, desemboca em um novo tipo de relação perceptiva entre o X transcendente (em-si) e a consciência (para-si), isto é, esta relação adquire um novo sentido, sentido até então ausente do ensaio sobre o ego transcendente: nos quadros de $C D G$, perceber o X é, acima de tudo, um fenômeno existencial, consequentemente, para a consciência, percebê-lo será ultrapassá-lo em direção a seu próprio nada de X; pois “a consciência, em seu para-si, ultrapassa o mundo em direção a si mesma. Ela é investida pelo em-si na medida exata em que é tomada pelo Nada" (SARTRE, 2010b, p. 463). Grosso modo, só haverá apreensão do X qualquer se e somente se a consciência for, de antemão, um nada de ser. A relação, uma vez enquadrada nestes termos, é necessário afirmar que a consciência, definida como Nada, existe para-si para além do X como aquilo que não é esse $X$ percebido/nadificado: a consciência é consciência não-tética de si mesma como consciência tética do X qualquer; a consciência dos Carnets só é consciência de si (tética ou não) no momento em que é consciência do objeto, este objeto sendo, por seu turno, o tema transcendente de sua nadificação ${ }^{20}$. A partir desta díade instituída pelo para-si e pelo em-si, "ser no mundo e ser tomado pelo Nada não são senão uma única e mesma coisa" (SARTRE, 2010b, p. 463): a teoria do Nada permite superar definitivamente o realismo e o idealismo, pois

20 A partir desta assertiva, seríamos capazes de evidenciar com mais clareza o que separa a consciência de $T E$ desta consciência dos Carnets: nos anos 1937, a consciência é consciência de si na exata medida em que é consciência do mundo; "com efeito, a existência da consciência é um absoluto porque a consciência é consciência dela mesma. Isto é, o tipo de existência da consciência implica ser consciência de si. E ela toma consciência de si na exata medida em que é consciência de um objeto transcendente. Tudo é claro e lúcido na consciência: o objeto está diante dela com sua opacidade característica, mas ela é pura e simplesmente consciência de ser consciência deste objeto, esta é a lei de sua existência. (...) Seu objeto está fora dela por natureza, e é por isto que em um mesmo ato ela o põe e o apreende. Ela apenas se conhece como interioridade absoluta" (SARTRE, 2003, p.98). Em CDG, uma vez o nada entrando em cena, será forçoso admitir que a consciência somente pode ser consciência de si na exata medida em que é consciência nadificadora do objeto, isto é, a consciência somente é consciência do X qualquer na exata medida em que ela, em seu ser mesmo, não é este $X$, quer dizer, na medida em que ela é um nada de ser. Doravante, afirmaremos que somente um ser que é, em seu ser, nada de ser, poderia operar um movimento intencional para fora de si mesmo. Nesse sentido, o nada cumpre um papel teórico bastante preciso aqui. 
Este princípio original confirma, contra o 'realismo' e o 'idealismo', que não há inicialmente o mundo de um lado e do outro a consciência, e, em seguida, uma dupla relação, em suma, a diferença entre esses dois modos de relação: não há ser-no-mundo senão precisamente no momento em que se institui, com um único gesto, uma relação indivisível - presença da consciência a si como abertura ao mundo, abertura ao mundo como presença a si (COOREBYTER, 2000, p. 265).

Havendo uma unidade sintética indivisível entre a consciência e o mundo, os Carnets dão, por tanto, um passo adiante em relação à $I M$ e apontam, como já notamos, um conceito de ser-do-mundo bastante diferente da obra de 1940. Aqui, a nadificação não será mais aquele ato duplo de, por um lado, pôr o mundo como totalidade sintética para, em seguida, recuar em relação a ele. A nadificação, tal como vislumbramos neste momento, sinaliza o fato de a consciência aparecer como negativa, ou seja, esta negatividade é "uma condição de possibilidade da experiência, como o que torna possível a existência de um objeto para a consciência" (MOUTINHO, 1993, p. 145-146). Para que a interdependência - mediada pelo nada - entre a consciência e o transcendente seja esclarecida, Sartre evoca a ideia do contanto. Aparentemente simples, a assertiva "a mesa está em contato com a parede", conduz-nos ao ser-no-mundo e, igualmente, ao Nada. Vejamo-la. Se quisermos realmente compreender o sentido ontológico dessa ideia, comecemos por notar que oscilamos entre duas ideias opostas ou, como escreve Sartre, antinômicas: "a ideia da plenitude imanente do em-si e a ideia do recuo absoluto do Nada" (SARTRE, 2010b, p. 464). A ideia de contanto deve ser compreendida como a relação íntima de ser entre dois objetos, logo, quando enunciamos que a mesa toca a parede, não dizemos que ela está ao lado dessa parede, nem que ela esteja o mais perto possível dela, e nem mesmo separada da parede por uma distância infinitesimal. Caso pretendamos manter uma distância, por menor que seja, entre dois objetos, Sartre observa que, além de não podermos dizer que eles se tocam, não podemos fundi-los um ao outro, pois o contanto não é fusão; assim:

(...) eis-me de volta à ideia de uma distância que, por menor que seja, ao menos separa os dois objetos. Mas, nesse momento, a ideia de contanto desaparece. Na verdade, se tento captar o que ela exige, vejo que é preciso, 
Dr. Gustavo Fujiwara [UFSP]

para que haja contanto entre as duas individualidades, que elas estejam uma para a outra sem distância, pelo menos em um ponto das suas superfícies e que, no entanto, estejam separadas. Mas, separadas pelo que? Por nada (rien) (SARTRE, 2010b, p. 464).

Deste excerto, é preciso concluir que somente através da consciência nadificadora pode-se conceber a relação de distância (ou proximidade) entre dois objetos: "de fato, uma cadeira não toca a parede a menos que seja levada à unidade de um mundo transcendido pela realidade-humana ${ }^{21}$ (...). A consciência está em contanto com o mundo" (SARTRE, 2010b, p. 465). Fazendo ecoa à proximidade absoluta de $T E$, embora galvanizada pelo nada, a relação de contanto entre a consciência e o mundo extirpa, ao mesmo tempo, o idealismo e o realismo na medida em que o mundo é "o em-si investindo a consciência e em contanto com ela, assim como ela o ultrapassa em seu nada" (SARTRE, 2010b, p. 465). Com efeito, a particularidade do Nada é a de que ele não pode subsistir como nada senão na condição de não se distinguir do que ele não é; em outros termos, o para-si não é para-si senão negando-se a si mesmo e desvanecendo sob a dependência do em-si que ele faz, assim, aparecer. Como será possível localizar em

21 A realidade-humana, deve-se fazer notar, é a tradução francesa (feita por Corbin) do Dasein de Heidegger. Sobre o sentido que essa tradução coloca, sugerimos a leitura da obra Heidegger en France (2001), de Dominique Janicaud. Além desta sugestão, Tomès, no prefácio à edição francesa de 2010 de Esquisse, precisa: "Pode-se certamente ver em Etre et Temps a origem da ideia segunda a qual o fato de existir recai sobre o homem como um modo de ser particular que supõe que ele não receba seu ser de fora, mas que ele o assume e seja responsável por ele. E é isso que Heidegger, em sua Lettre sur l'humanisme, denunciara: o contrassenso existencialista sobre sua definição do Dasein, relembrando que é necessário apreender o homem a partir do ser e não de uma pretensa essência de homem que daria sua especificidade; posição dita humanista que terá de uma certa maneira Sartre (...)." (TOMES, 2010, p. 34).

Em $C D G(2010$ b, p.466), o próprio Sartre comenta seu contanto com a filosofia heideggeriana através da tradução francesa de Que é Metafisica? (1938); lá ele escreve: "Certamente, se Corbin não tivesse publicado sua tradução de Was ist Metaphysik?, eu não a teria lido. E, se eu não a tivesse lido, não teria me aventurado, na última Páscoa, na leitura de Sein und Zeit".

No "Caderno III", o filósofo sublinha que a realidade-humana, o ser-no-mundo \& seu ser-em-situação, seriam capazes de afastar os perigos idealistas, naturalistas e materialistas: "O erro do idealismo está em colocar o espírito em primeiro lugar. O erro do materialismo e de todos os naturalismos é fazer do homem um ser natural. A religião do homem, considerado como espécie natural: o erro de 48, o pior de todos, o erro humanitário. Contra isso, estabelecer a realidade-humana, a condição humana, o ser-no-mundo do homem e seu ser-em-situação" (SARTRE, 2010b, p. 299). Contra este fundamento humanista que considera o homem uma espécie, o dito "humanismo existencialista" insistirá no fato de que o homem é um nada em busca do ser: consciência e mundo são necessários um para o outro. Em $E N$, à sombra dessas reflexões, veremos que a natureza humana (uma essência que precederia a existência) é uma vã tentativa que busca substancializar o homem, torná-lo uma coisa à maneira inerte do ser-em-si. Fazendo do homem, um ser pelo qual o nada vem ao mundo, um ser cuja existência precede a essência, Sartre elimina, desta lida, qualquer forma de substancialização da consciência: "mas que queremos dizer nós com isso, senão que o homem tem uma dignidade maior do que uma pedra ou uma mesa?" (SARTRE, 1964, p. 243). 
Dr. Gustavo

Fujiwara [UFSP]

$E N$, uma das consequências diretas desse nada no bojo da consciência será o seu reenquadramento conceitual como presença a si e não coincidência a si: existir, para a consciência, é não ser o que é e ser o que não é, é ser consciência reflexo-refletidora. Esta fórmula, concebida para caracterizar a estrutura ontológica de um ser que é seu próprio nada de ser, ser-para-si, "vai contra as representações deterministas alheias ao modo de ser do para-si e tratam a 'realidade-humana', ser-no-mundo, como uma realidade no meio do mundo" (MOUILLE, 2000, p. 73), em suma, como um ser-no-meio-do-mundo (être-au-milieu-du-monde). Ora, afirmar que a consciência é presença a si indica que, presente a si (e não idêntica a si), ela é, ao contrário da plenitude maciça do ser-em-si, um ser que é nada de ser: "a presença a si supõe que uma fissura impalpável deslize no ser, o para-si é presença a si porque ele não é de fato si. A presença a si é a marca viva do nada" (COOREBYTER, 2013, p. 393). Assim, dissolvendo toda e qualquer interpretação determinista da consciência (ou seja, toda e qualquer interpretação que a conceba à maneira de um ser-em-si), nosso filósofo desvela um ser-para-si nadificador que mantém uma relação dicotômica (porém em contato) com o ser-em-si. Drôle de Guerre, ao conceber a consciência como nada, reestrutura o díptico do real e do irreal (imaginário) de L'Imaginaire em díptico entre ser e nada. Agora, não se deverá falar da nadificação como uma fuga do mundo, mas, muito pelo contrário, como um ato negativo que faz, justamente, irromper o mundo e, nesse mesmo movimento, faz com que a consciência seja presença a si ${ }^{22}$. Nas tramas teóricas da obra em tela, ter consciência, por exemplo de uma árvore, significa ultrapassá-la rumo a seu próprio nada de árvore, pois "a consciência existe para-si além da árvore como aquilo que não é a árvore" (SARTRE, 2010b, p. 463). N'outras palavras, ter consciência é, imediatamente, distinguir-se do objeto (de sua presença) ao nadificá-lo. Se em $T E$ a consciência "tropeçava em uma presença", aqui, ela também tropeça nessa presença, mas nadificando-a: "a ligação nadificadora do reflexo e do refletido faz com que ela (a consciência) somente possa ser para si mesma (consciência consciente de si) ao se refletir como sendo precisamente nada do mundo onde há essa árvore" (SARTRE, 2010b, p. 463). Embora notemos aqui uma substanciosa diferença em relação às primeiras obras fenomenológicas, a assunção da consciência ao nada ainda não pode ser amplamente nomeada como uma teoria própria ao dis-

22 A originalidade de $E N$ em relação à $T E$ poderia, pensamos, ser mensurada por esta presença a si: no opúsculo sobre o ego transcendente, a consciência de primeiro grau era consciência irrefletida de si, mas nem por isso Sartre indicava nessa consciência uma presença a si. Em regime de ontologia fenomenológica, a presença a si, enquanto marca indefectível do nada que constitui a consciência, arrimará (nós veremos isso) a intencionalidade a um desejo que será compreendido como desejo de ser, isto é, como desejo de identidade a si sob a forma ideal do em-si-para-si. 
Dr. Gustavo Fujiwara [UFSP]

curso de ontologia fenomenológica, pois deixa em suspenso a análise da natureza do Ser, bem como a relação entre o para-si e o em-si:

Nos Carnets, a ontologia ainda não está em seu lugar, com suas duas 'regiões incomunicáveis', para-si, em-si, que fazem da intencionalidade uma relação violentamente disjunta no momento mesmo onde ela se estabelece e que recusam toda instância suscetível de estabilizá-la, de unificá-la ao ultrapassá-la ou precedê-la. Mas, no registro que é, de início, aquele deste diário, aquele do questionamento de si-em-guerra, e da autenticidade ou da inautenticidade desse si, Sartre opera, bastante concretamente ou quase contra a sua vontade, a prova da impossibilidade deste envolvimento da 'realidade-humana' pelo Ser, prova que vai, precisamente, conduzi-lo a pensar o Nada (SIMONT, 2015, p. 44).

Assim, Sartre deverá, em $E N$, além do Nada, pensar a possibilidade de um Ser que não tenha sua existência dependente da consciência, dependência que faria com que caíssemos no idealismo fenomenológico de Husserl que reduz "o mundo ao estado de correlativo noemático da consciência" (MOUTINHO, 1993, p. 146), reino do subjetivismo transcendental ${ }^{23}$. Ora, se a ideia do nada é capaz de superar, de um só golpe, o idealismo e o realismo, essa superação deverá ser construída a partir do estudo da taxonomia do Ser dividido em duas regiões (em-si/para-si) que são independentes na interdependência de uma sob a outra. A busca pelo Ser deslindará, além da superação definitiva do noema irreal e ideal de Husserl (bem como a superação da hylé), a especificidade do para-si enquanto um ser que é seu próprio nada de ser sem ser, contudo, seu próprio fundamento de ser: “(...) o para-si não é fundamento de seu ser-como-nada-de-ser, mas ele funda perpetuamente seu nada-de-ser" (SARTRE, 2010a, p. 667). Ora, mas esta taxonomia do Ser (em-si/para-si), tal como ocorre em L'être et le néant, é uma outra história e fica, portanto, para um outro momento.

23 Em Ideias I (1913), §90, Husserl aclimatará a fenomenologia com esse novo conceito de fenômeno (o noema), conceito que deverá se reportar aos fenômenos no sentido "ôntico" da palavra, ou seja, fenômenos que não são partes reais da consciência, fenômenos dados segundo os modos subjetivos de doação. Tal conceito, será fundamental para que a fenomenologia fale em um a priori da correlação entre consciência e objeto. Entrementes, por não ser parte real da consciência, o noema afirma seu aspecto subjetivo, ou seja, "em regime de redução fenomenológica é o próprio mundo que se torna subjetivo" (MOURA, 2006, p. 22). Como meio ideal pelo qual a realidade se oferece à consciência, o noema acentua o modo subjetivo de doação, isto é, ele acentua, finalmente, aquela esfera normativa que regula e confere sentido aos objetos mundanos. 
BEAUVOIR, Simone de. La force de l'âge. Paris: Gallimard, "Folio", 1980.

BERNET, Rudolf. "Le temps irréeal (Sartre)"; in: Bulletin d'analyse phénoménologique VIII, 1. Belgique: 2012, pp. 261-272

CABESTAN, Philippe. L'Imaginaire: Sartre. Paris: Ellipses, 1999.

COOREBYTER, Vincent de. Sartre face à la phénoménologie: Autour de "L'intentionnalité" et "La transcendance de L'ego". Paris: Éditions OUSIA, 2000.

. "Présence à soi"; in: Dictionnaire Sartre. Sous la direction de François Noudelmann et Gilles Philippe. Paris: Éditions Honoré Champion, 2013, p. 393.

DERRIDA, Jacques. La voix et le phénoméne. Paris: PUF, 2009.

HUSSERL, Edmund. Ideias para uma fenomenologia pura e para uma filosofia fenomenológica. Introdução geral à fenomenologia pura. Tradução de Marcio Suzuki, prefácio de Carlos Alberto Ribeiro de Moura, São Paulo: Idéias e Letras, 2006.

JANICAUD, Dominique. Heidegger en France. Paris: Hachette Littérature, 2001.

MASSELOT, Nathanael. "L'ontologie sartrienne est-elle une phénoménologie transcendantale?"; in: Methodos. Savoir et textes, 2012, pp. 1-29.

MOUILLE, Jean-Marc. Sartre: Conscience, ego et psyche. Paris: PUF, 2000.

MOURA, Carlos Alberto Ribeiro. "Prefácio"; in: Ideias para uma fenomenologia pura e para uma filosofia fenomenológica. Introdução geral à fenomenologia pura. Tradução de Marcio Suzuki. São Paulo: ed. Idéias e Letras, 2006.
MOUTINHO, Luiz Damon Santos. Psicologia e fenomenologia em Sartre. São Paulo, USP: tese de dissertação de mestrado, 1993.

SARTRE, Jean-Paul. La transcendance de l'ego et autres textes phénoménologiques. Texte introduits et annotés par V. de Coorebyter, Paris: J. Vrin, 2003

. "Carnets de la drôle de Guerre"; in: Les mots et autres écrits autobiographiques. Paris: Gallimard, "Bibliothèque de la Pléiade", $2010 \mathrm{~b}$.

. L'être et le néant - Essai d'ontologie phénoménologique. Paris: Éditions Gallimard, "Tel”, 2010a.

. L'Imaginaire. Paris: Éditions Gallimard, "Folio", 2010c.

. A Imaginação. São Paulo: Abril Cultural, Coleção “Os Pensadores”, 1973.

. Situations, IX. Mélanges. Paris: Éditions Gallimard, 1987.

O existencialismo é um humanismo. Tradução e notas de Vergílio Ferreira. Lisboa: Editorial Presença, 1964.

SIMONT, Juliette. “Genèse du 'Néant', genèse de L'être et le néant (À propôs de la morale et de l'ontologie de Sartre)"; in: Sartre. L'être et le néant. Nouvelles lectures. Textes réunis par Jean-Marc Mouille et Jean-Philippe Narboux. Paris: Les Belles Lettres, 2015, pp. 35-56. "Notes à propos de Carnets de la Drôle de Guerre"; in: Le Mots et autres écrits autobiographiques. Paris: Éditions Gallimard, "Bibliothèque de la Pléiade”, 2010.

TOMÈS, Arnaud. Préface à L'Esquisse d'une théorie des émotions"; in: Esquisse d'une théorie des émotions. Paris: Hermann, 2010

VAUDAY, Patrick. “Sartre: l'envers de la phénoméno- 
logie"; in: Rue Descartes, $\mathrm{n}^{\circ}$ 47. Paris: Collège internacional de Philosophie, 2005, pp. 8-18.

GADAMER, H.G. - Geleitwort. In: Biemel, W. e Hermann, F-W (editores) - Kunst und Technik - Frankfurt a. M., 1989.

HEIDEGGER, Martin. Seminários de Zollikon. Ed. 2a. São Paulo. Editora Vozes e Editora Universitária São Francisco.. Trad. De Gabriella Arnhold e Maria Fátima de Almeida Prado. 2009.

.Kant und das Problem der Metaphysik. Frankfurt am Main: Vittorio Klostermann, 1991.

Ser e tempo. Ed. 5a. Petrópolis - RJ. Editora Vozes e Editora Universitária São Francisco. Trad. De Márcia de Sá Schuback, 2006.

HUSSERL, E. Ideias para uma fenomenologia pura $e$ para uma filosofia fenomenológica. Ed 2a . Aparecida SP. Editora Ideias e Letras. Trad. de Márcio Suzuki. 2006.

INWOOD, Michael. Dicionário Heidegger. Rio de Janeiro - RJ. Jorge Zahar Editor. 2002.

MOURA, Carlos Alberto R.. Prefácio à segunda edição de Ideias para uma fenomenologia pura e para uma filosofia fenomenológica. Presente em: HUSSERL. E. Ideias para uma fenomenologia pura e para uma filosofia fenomenológica. Ed 2a. Aparecida - SP. Editora Ideias e Letras. Trad. de Márcio Suzuki. 2006.

STEIN, Ernildo. Lições preliminares sobre o $\$ 44$ de Sein und Zeit. Ijuí, RS. Editora UNIJUÍ. 2006.

Mundo e Subjetividade: o núcleo da diferença entre Husserl e Heidegger. Presente em: Às voltas com a questão do sujeito, posições e perspectivas. Org. César Augusto Battisti. Paraná - RS. Editora UNIOESTE e UNIJUÍ. 2010.

Seminário sobre a verdade. Lições preliminares sobre o $₫ 44$ de Sein und Zeit. Petrópolis. Edi Às voltas com a metafísica e a fenomenologia. Ijuí, Rio Grande do Sul - RS. Editora Unijuí, 2014.
- Destruição da metafísica ou crise da metafísica e crise da estética (simetria e reversibilidade). Presente em: Revista do Programa de Pós Graduação em Letras da UFSM. No 54. Junho de 2017.

TORRES, Jesús Vásquez. Subjetividade transcendental e transcendentalidade do Dasein: aproximações entre Husserl e Heidegger. Presente em: Revista Perspectiva Filosófica. V. VII, número 14. Jul/dez./2000. P. 72. 